\title{
Factors Determining Students' Low Usage of Mobile Tools in their English Vocabulary Learning
}

\author{
Diana CoJOCNEAN \\ University of Exeter, $U K$
}

Received: 5 December 2015 / Accepted: 22 January 2016

ISSN: $1697-7467$

\begin{abstract}
The article is based on the results of a large scale mixed methods study which took place in Romania in 2014. The study explored high school students' use of digital vocabulary English learning strategies and the attitudes of Romanian students towards learning vocabulary in second language acquisition with digital tools. The results of the main study indicated that the participants had a low usage of digital tools and strategies in their vocabulary learning and that the majority of the participants showed neutral attitudes towards the use of mobile assisted learning (MALL) tools in their vocabulary learning. The data also revealed that certain factors determine students' low usage of digital tools in second language acquisition in their vocabulary learning. These factors were: the lack of a 'culture' associated with the use of digital tools in the language classroom, personal learning style, some pedagogical issues associated with digital tools, lack of teacher guidance, the view of digital tools as simply entertaining tools, students' multitasking behavior in association with the use of their device, a preference for unconscious learning of vocabulary and the level of motivation to use technology for second language acquisition.
\end{abstract}

Keywords: MALL, CALL, digital tools, Apps, vocabulary learning, attitudes, second language acquisition, digital learning strategies.

Factores que determinan la baja utilización de herramientas móviles por parte de estudiantes en su aprendizaje de vocabulario en lengua inglesa

RESUMEN: El artículo se basa en los resultados de un estudio a gran escala con métodos mixtos que tuvo lugar en Rumanía en 2014. El estudio exploró la utilización de estrategias digitales para el aprendizaje de vocabulario en lengua inglesa por parte de estudiantes de secundaria y las actitudes de los estudiantes rumanos hacia el aprendizaje del vocabulario de un segundo idioma con herramientas digitales. Los resultados del estudio principal indican que los participantes tenían un bajo uso de herramientas y estrategias digitales en su aprendizaje de vocabulario y que la mayoría de los participantes mostraron actitudes neutrales hacia el uso de herramientas móviles (MALL) en su aprendizaje del vocabulario. Los datos también revelaron que ciertos factores determinan el poco uso de los alumnos de las herramientas digitales en la adquisición de un segundo idioma en relación al aprendizaje del vocabulario. Estos factores son: la falta de una "cultura" asociada con el uso de herramientas digitales en la clase de lengua, el estilo personal de aprendizaje, algunas cuestiones pedagógicas asociadas a las herramientas digitales, la falta de la guía del profesor, la percepción de las herramientas digitales como meras herramientas de entretenimiento, un comportamiento multitarea de los estudiantes en relación con el uso de su dispositivo, una preferencia por el aprendizaje inconsciente del vocabulario y el nivel de motivación para utilizar la tecnología para la adquisición de un segundo idioma.

Palabras clave: MALL, CALL, herramientas digitales, Apps, aprendizaje de vocabulario, actitudes, adquisición de una segunda lengua, estrategias digitales de aprendizaje. 


\section{INTRODUCTION}

The advent of technological affordances may have impacted the way students look at vocabulary learning and more importantly the way language learning in general fits into the more global digital context. According to a survey conducted by Samsung(C) on 1911 students aged 16-19 (Chilianu, 2013), 70\% of Romanian high school students have a smartphone, $60 \%$ own a laptop whereas $19 \%$ have tablets. The same study uncovered that $92 \%$ of the participants use social networking on a regular basis. We know, therefore, that digital devices play a significant role in students' personal lives but little is known about how students interact with their digital tools in their studying space.

In the context of the current study, attitude is defined as the learner's desire to respond favorably, neutrally or unfavorably to the use of digital resources for learning vocabulary in English. Although researchers and developers may have positive attitudes towards the use of digital tools in learning, it is interesting to know to what extent this interest is also shared by learners themselves and whether learners feel or not motivated by the opportunities offered by mobile technologies. One of the aims of the current study was to analyze the factors associated with learners' degree of involvement in the use of mobile assisted language learning MALL tools for learning vocabulary in English. The power of mobile technologies to motivate learners is rather limited and the current paper explores several factors which may account for students' low usage of digital tools in their vocabulary learning (Rogers, 1962).

\section{Mall AND CAll STRATEgies fOR Vocabulary LEARNing}

Vocabulary learning in a computer and mobile assisted language learning context refers to the possibilities offered by technology in order to learn or consolidate English vocabulary. The technological opportunities can have either an incidental or explicit nature but most often technology encompasses these two approaches.

In the current study, I grouped the digital learning strategies used with digital tools in four types, based on the features that characterize technology enhanced tools. Therefore, the four types of digital learning strategies are: social, determination, metacognitive-cognitive and memory.

The quantitative survey data indicated that determination digital strategies $(M=2.83$, $\mathrm{SD}=0.62$ ) are used most by Romanian students. These represent strategies which help one find the meaning of a new word using a digital device. The determination digital strategies are followed by the social digital strategies $(\mathrm{M}=2.63, \mathrm{SD}=0.76)$. The social digital strategies relate to the principles of social constructivism and they are mainly characterized by learning while interacting with others in an online environment. Most often, they are associated with social networking and gaming. The metacognitive-cognitive category $(\mathrm{M}=2.05, \mathrm{SD}=0.72)$ includes strategies which focus on the learning or consolidation of new vocabulary using a digital device. I combined the metacognitive-cognitive strategies in one category as strategies may fall in one category or another depending on how the student uses the strategy. For example, using a vocabulary learning app could be either a cognitive or a metacognitive strategy. If the learner uses it only to learn vocabulary, then it is a cognitive strategy, but if the learner 
uses it independently only to improve the knowledge he/she has on some words, then it is a metacognitive strategy. Accordingly, there is a limitation behind this categorization as the same strategy may be included in more than one category, depending on how it is used or on the user's learning behavior. The memory digital strategies $(\mathrm{M}=2.05, \mathrm{SD}=0.67)$ represent strategies that use a device, a program or an app to enable the memorization of new words. Therefore, the categorization of digital strategies is determined by how the learners use the device or the app/program, by their learning behavior, which can be directed either towards learning or entertainment. These two purposes often overlap in an online environment as students can simply start using an app for vocabulary learning as a form of entertainment but with learning outcomes as well.

Thus, in the context of the current study, digital tools include computer and mobile assisted language learning tools such as: computer-assisted vocabulary learning programs, computer-based vocabulary exercises, online dictionaries, lexical concordancers, electronic lexical glosses, the use of social networking sites as well as the use of other websites which would give the students incidental opportunities to encounter new words. The mobile assisted language learning tools include language learning apps but also apps which are not designed for vocabulary learning in particular.

The "most common MALL activity reported in the literature is vocabulary learning" (Pegrum, 2014:131). Vocabulary learning research is connected with vocabulary apps in order to better explain how vocabulary learning occurs in a mobile learning episode (Underwood, 2014). Knowledge about words occurs during different episodes and vocabulary apps have embedded vocabulary learning tools, such as flashcards, dictionary tools, notebook tool, gamelike activities, derived from what research stated that works best for vocabulary learning.

On the other side, the pedagogic and technical qualities of language learning apps do not necessarily match their linguistic values for EFL teaching and learning, suggesting that though some apps may be very attractive they may not be based on sound linguistic content providing a rather fragmented language practice (Pareja-Lora et al. 2013). There are in fact only few studies which show designs for seamless vocabulary learning and which render features that connect incidental and explicit learning activities (Wong, 2013). Since 2007 the approach with MALL is behaviorist and teacher-centered as drill and repetition type of activities are still largely present in the apps (Burston, 2014). Learners interpret and make use of designs in their own way and most often they do not use the features of an app the way their designers imagined (Stockwell and Hubbard, 2013). Underwood et al. (2014) support participatory designs for self-vocabulary learning by making use of social and mobile technologies. Therefore, they highlight the fact that within a learning app, learners should be allowed to configure the way they want to manage their vocabulary learning (Underwood et al.2014).

A close investigation of mobile apps for language learning would show that these apps are not designed to be used in a formal environment, during regular instruction, but rather by students individually, in an informal learning situation (Gimenez et al. 2009). Meta-design could stand for the bridge between formal and informal use of MALL tools in second language acquisition. Therefore, it is not the technology used that can impact on learning, but the way one uses technology to support the most effective individual learning activities (Luckin et al., 2012). Some researchers focused on investigating the influence of technology-enhanced instruction on language learning, shedding light on their positive effects. However, students' 
perspective and actual digital word learning behavior have been overlooked in research (Abrams, 2002; Al-Jarf, 2004; Blasszauer, 2001; Brandl, 2002; Chikamatsu, 2003; Jogan, Heredia and Aguilera, 2001; Meskill and Anthony, 2005).

\section{RESEARCH METHODOLOGY}

\subsection{Context of the study and participants}

Nine high schools were selected through geographical cluster sampling (Teddlie and Tashakkori, 2009) from three different cities in Romania in 2014. Within the schools, the classes were randomly selected by the teachers who administered the questionnaire, ensuring a balanced distribution of academic profiles, language programs and age. The total number of participants in the current study was 1,239. The participants were distributed across four academic profiles: math-ICT $(33 \%)$, humanities $(23 \%)$, science $(22 \%)$ and economic-technical $(22 \%)$. The mean age for the entire sample was 16.46 . The gender distribution indicated that $60 \%$ of the sample population in the study was female whereas $40 \%$ was male. As to the language program distribution in the sample, 52\% were enrolled in a normal program, $38 \%$ were Intensive English whereas $10 \%$ were enrolled in a bilingual program. The mean length of English language learning for the entire sample was of 9.31 years. The study was a mixed methods one, combining focus group discussions with a questionnaire that had three main scales:

- The vocabulary learning strategies scales.

- The digital tools for vocabulary learning scale.

- The attitudes towards learning vocabulary with digital tools scale.

- The current study uses the results from focus group discussions and from the attitudes towards learning vocabulary with digital tools scale.

\subsection{Instruments and data collection procedures}

The study used a qualitative $\rightarrow$ quantitative sequential mixed-methods sampling strategy which consisted of a volunteer qualitative sample (43 students in five focus groups, from 5 high schools) and a cluster geographical quantitative sample $(1,239$ students in 9 high schools), (Teddlie and Tashakkori, 2009). In order to collect quantitative data, cluster sampling was combined with random sampling. For the qualitative data, cluster sampling was combined with convenience volunteer sampling, which implied that students enrolled in the same high schools from which the quantitative data were collected, volunteered to participate in the focus group discussions. The qualitative data were collected using the focus group interview whereas the quantitative data were collected using the attitudes towards learning vocabulary with digital tools scale which was based on my own understanding of the digital tools students use for vocabulary learning, on the available literature on MALL and CALL but also on the results from the focus group discussions. The questionnaire was a Mixed Methods one and it included both closed-ended statements and a comment column, which allowed the participants to add other aspects. The thematic analysis of the data in the comment column of the questionnaire was embedded in the thematic analysis of the focus 
group data, being treated as qualitative data. The attitudes scale is a 14 item instrument that measures students' attitudes towards learning vocabulary with digital tools on a 1-5 point Likert scale ( $1=$ strongly disagree; $2=$ disagree; $3=$ neither agree, nor disagree, $4=$ agree, $5=$ strongly agree). The scale is reliable and valid (with an alpha coefficient of .77), (Field, 2009). The software package used in the analysis of quantitative data was SPSS 21.

\section{SuRvey, ReSUlts AND Discussion}

The survey data revealed that Romanian high school students prefer the following digital tools for vocabulary learning: online dictionaries, translation apps, online games and social networking web sites. Also visualization of a word is a highly rated strategy and looking up online for an image representing the meaning of a new word is a frequently used strategy. Likewise, learning new words from social networking as well as chatting in English are frequently used strategies by Romanian learners. These findings are not surprising given students' age and interests. It also shows students' preference for learning while doing enjoyable activities, which mostly feature learning in online social contexts. On the other side, the least used digital tools for vocabulary learning are: vocabulary learning apps, online vocabulary quizzes, corpus websites, online vocabulary exercises and computer assisted vocabulary learning programs.

In order to determine the kind of attitudes students have towards learning English vocabulary with digital resources, the rating for all the 14 items in the attitudes scale were summed. The maximum mark was 70 and the minimum mark was 14. Based on this range, the participants' scores were divided into three levels to determine the kinds of attitudes they have towards learning English with digital resources. The score range for the three levels were as follows: unfavorable attitudes (score range 14-32), neutral attitudes (score range 33-51) and favorable attitudes (score range 52-70).

In Table 1 the frequencies of use also reveal that $71.8 \%(n=777)$ of the participants have neutral attitudes, $24 \%(\mathrm{n}=346)$ have favorable attitudes, whereas only $4.3 \%(\mathrm{n}=4.3)$ have an unfavorable attitudes.

Table 1: Students' overall attitudes towards the use of technology for vocabulary learning.

\begin{tabular}{|c|c|c|}
\hline Type of attitude & Percentage & $\mathbf{n}$ \\
\hline Unfavorable: $14-32$ & 4.3 & 50 \\
\hline Neutral: $33-51$ & 71.8 & 777 \\
\hline Favorable: $52-70$ & 24.0 & 346 \\
\hline
\end{tabular}

$\mathrm{N}=1173$

Furthermore, the data in the focus group explicate students' neutral attitudes towards the use of technology enhanced tools for vocabulary learning. Students' neutral attitudes indicate that they are neither in favor nor against the use of technology enhanced tools for vocabulary learning. In the following sections the main reasons which account for students neutral attitudes are discussed. 


\subsection{Factors determining students' low usage of digital tools for vocabulary learning}

\subsubsection{Preference for apps/tools enabling unconscious learning of vocabulary}

During the focus group discussions, the participants noticed various features of the apps they had used. The majority of them pointed out that in apps or even in some computer assisted vocabulary programs words appear in isolation, similar to words in a word list, but on a screen, therefore this would not stir their interest in particular, emphasizing the fact that the apps they are familiar with are not very stimulating: "We don't usually learn new words from apps designed for learning words, we learn them from context. We do learn words from apps but not from those vocabulary learning apps" (participant E, male, 15, school C.G).

Additionally, using an app is very similar to conscious learning of vocabulary. One participant from school C.G asserted: "When you download an app, then you consciously want to learn something. And we don't want to consciously learn something in our free time" (participant F, male, 17, school C.G). Another participant also supported this statement by saying: "Students will not use vocabulary learning apps in their free time let's say as they don't want any 'conscious learning after school" (participant B, male, 16, school C.G). These two statements clearly suggest the fact that students consider there is a difference between formal and informal learning and that at least at this stage, they are separate.

Moreover, students' lists of preferred games and apps show that none of them is particularly vocabulary learning oriented, however, naming them in the questionnaire means that they recognize their learning value and potential. The data uncovered students' preference for learning words in a meaningful context, while playing a game, while reading something they enjoy or while using a thought-provoking app. All these digital tools provide not only a context, but also several opportunities to encounter new words in a more appealing way. According to most of the students, an online game is much more enjoyable than a vocabulary learning app, in a game they are able to learn words from context whereas in an app or in a vocabulary learning program, word learning is a more conscious process. The following quotes illustrate the participants' preference for online games: "In a strategy game you learn loads of words, and you also learn them easily because you learn them while doing something that you really like. You like what you play, what you see in the game, the information about the words stays with you much longer thus" (participant G, male,15, school C.G).

\subsubsection{MALL tools as sources of entertainment}

Some participants in the focus groups underlined the fact that they perceive these digital tools mostly as sources of entertainment, rather than learning. When they use their phone or tablet, their mind is not focused on learning anything. Even if they used an app, they would still be tempted to do something else, as the following examples show: "I am tempted to do something else on the PC or tablet, while doing exercises, for example, chat with friends, play a game, I'm not focused to learn” (participant B, female, 16, school O.G)./“I think the 
temptation would be too big, we can't generally be on one app only, we would be tempted to use others as well, to entertain ourselves" (participant D, male,16, school C.G). Given the fact that students use apps mostly during their free time, it is understandable that their digital behavior is characterized by multitasking and by considering their device a source of entertainment.

Likewise, another study (Strainiu and Georgescu, 2015) identified the types of apps their participants prefer and their results showed the lack of educational apps in students' preferences. Also their participants identified entertainment and socializing opportunities as the most important features of any app (Strainiu and Georgescu, 2015).

\subsubsection{Motivation to use technology for language learning}

Some of the participants in the focus groups also put forward the idea that no matter what resources one uses, one still needs to allocate time for them. Therefore, even though students have access to technology enhanced tools, it is completely useless without the learners' intent and determination to learn. The following quotes also indicate this: "It would be interesting to learn from apps, but we probably wouldn't allocate enough time to review the words, so then it is not very helpful" (participant G, male, 16, school O.G)./"Apps might be helpful, if we actually used them" (participant C, female, 17, school A.V).

The majority of the students in the focus groups have installed a dictionary on their handheld device, which they use for looking up unknown words and for writing up words in a list as the following quote suggests: "I write new words on my phone so that I can go back to them" (participant E, female, 16, school O.G). However, another student in the same focus group replied to this: "If you don't go back to the words you write in that list, it just doesn't matter where you write them" (participant $\mathrm{C}$, female, 16 , school O.G), suggesting that only relying on a device to remember the words for you, does not help you retain new vocabulary. This factor indicates that simply owning a device doesn't mean students will use it for learning purposes as well.

\subsubsection{The lack of a MALL culture in mainstream schools}

One of the questions during the focus group discussions focused on students' awareness as to the existence of various apps designed for vocabulary learning in English. Based on students' replies, most of the respondents were not familiar with apps designed for vocabulary learning. The participants mentioned that one of the reasons why they do not look at digital tools for vocabulary learning very enthusiastically is because nobody recommended their use for language learning. For example the following quote suggests this: "Also a reason which determines us using or not using an app is whether it is or not a recommended app. If nobody recommends us any app, it is very unlikely to search it ourselves. We sometimes don't know what to download, there are so many apps up there "(participant D, male, 15, school C.G.).

Likewise, most of the students in the focus groups also remarked that there might be more chances to get familiarized with apps if the school recommended: "We don't go home 
and start looking for apps usually. If somebody qualified shows them to us, then there are more chances to use them" (participant F, female, 18, school G.S)./ "We would probably use such apps if the teacher recommended them, if they told us exactly what apps to download. I think it would add more variety to our lessons, learning, maybe" (participant $\mathrm{D}$, male, 17, school N.B). As a result of the focus group discussions, but also based on my observations, most of the students in these focus groups believe that it is also the school's responsibility to promote the possibilities offered by technology in their learning as the following quote shows: "I also think that it is the school which should take care of this aspect. When you go home from school, there is little chance that you would start looking for a learning app" (participant A, female, 18, school G.S).

\subsubsection{Lack of teacher guidance}

The lack of a MALL culture in mainstream schools is connected to teachers' guidance and training. If students need guidance as to how to use these tools in their formal learning in the classroom, teachers also need training in order to be able to incorporate these tools in their teaching. Such initiatives have already taken place in Romania (e.g. the MLEARN project) but little has been achieved in terms of curricular integration of MALL tools in the foreign language curriculum. Also some researchers have shown that learners tend to incorporate learning resources recommended by their teachers suggesting that teacher behavior is likely to influence students' self-directed use of technology (Lai, 2014; Lai et al, 2014; Gray, Chang and Kennedy, 2010 cited in Lai, 2015, Garcia Laborda et al.,2011).

Teacher guidance is needed as, according to the participants, students neither can make a good selection of these tools nor they can use these tools constructively in the classroom. Engaging students with MALL tools in their formal learning is entirely dependent on the teacher providing such opportunities in the classroom and on the educational authorities providing the infrastructure. At the moment the MLEARN project is the first of its kind aiming at delivering teacher training programmes on mlearning for primary, secondary and special schools. The MLEARN project aims at promoting teacher development of mobile learning practices in the Netherlands, the UK, Romania, Italy and Greece.

\subsubsection{Individual learning style}

All of the above factors weigh differently when it comes to students' use of MALL tools for vocabulary learning. However, another important factor would also be individual learning style. This factor was also noticed by some of the students in the focus group. There is a connection between personal learning style and the use of digital devices as the following quote shows: "I think the matter of 'usefulness' depends again on the type of person you are. Maybe some people learn better from apps, maybe others learn better from listening to music" (participant A, female, 15, school G.S)".

In this context, according to Kolb's experiential learning model there are four learning styles: accommodator, assimilator, converger and diverger, (Kolb, 1984).

There are apps which are suitable for every type of learning style as in figure 1. Accordingly, learners are likely to choose the type of app that matches their learning style and preference as well (Robinson and Reinhart, 2014). 
Figure 1. ELM Learning Styles, Preferences for Learning with Mobile Devices Source: (Robinson R., and Reinhart J., 2014).

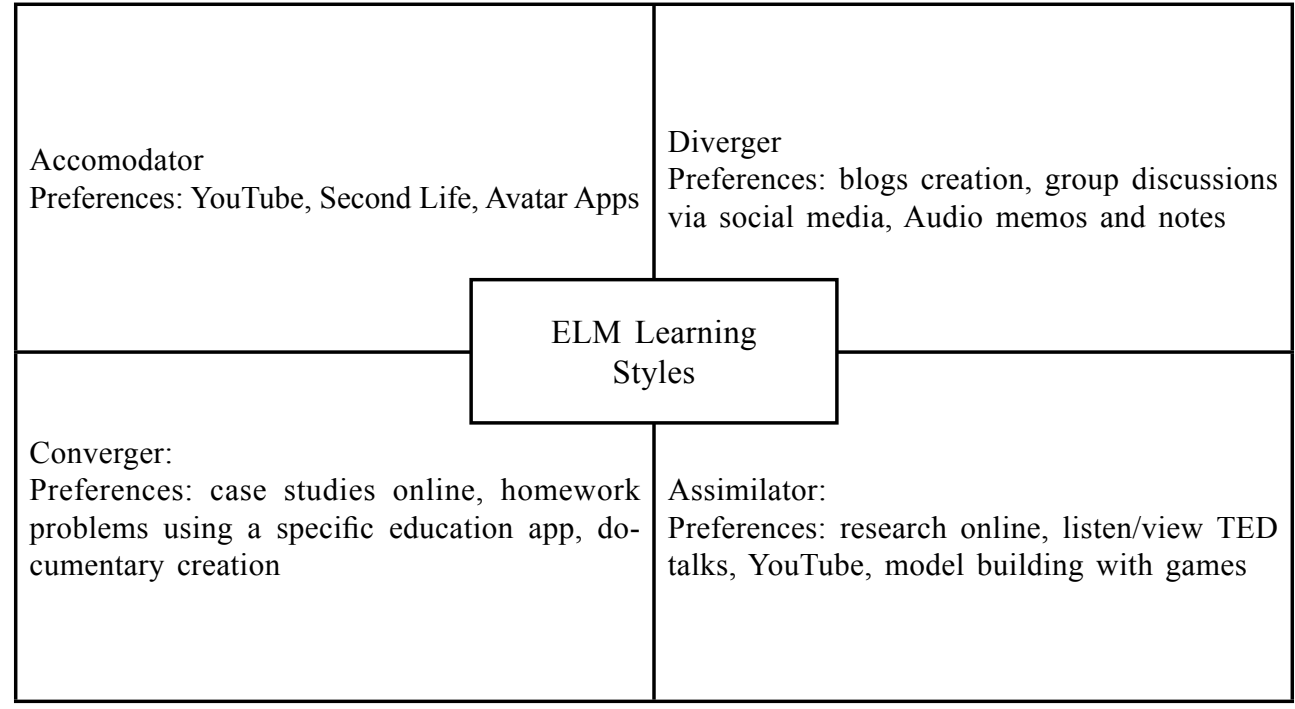

\subsubsection{Pedagogical issues associated with MALL tools}

Another factor which accounts for students' low usage of digital tools is related to some pedagogical issues associated with the available apps. The apps on the market are not meant to meet the needs students have in the classroom. First of all, they do not go hand in hand with the topics students focus on during their foreign language lessons, therefore they cannot contribute to students' recycling of learnt vocabulary in class. Moreover, according to the participants, the tasks these apps provide are not challenging enough, this being another reason for which students would rather use apps that are not necessarily vocabulary learning oriented. Students' potential superficial engagement with mobile technology for language learning could be related to the pedagogic features of the available apps as some MALL tools may not necessarily involve deep cognitive processing (Ushioda, 2013).

\subsubsection{Students' personal space}

Once students have downloaded an app, they clearly set their mind to learn words from it, equaling conscious learning. According to students, using an app is very similar to conscious learning of vocabulary. One participant from school C.G asserted: "When you download an app, then you consciously want to learn something. And we don't want to consciously learn something in our free time" (participant F, male, 17, school C.G). Another participant also supported this statement by saying: "Students will not use vocabulary learning apps in their free time let's say as they don't want any 'conscious learning after school" (participant B, male, 16, school C.G). 
It is considered that students' use of digital tools for their vocabulary learning is also strictly dependent on the extent to which they have accepted ubiquitous learning in their lives. In this context, some learners may regard mobile learning as an intrusion into their personal space which may influence their acceptance in formal learning (Dias, 2002). This means that students would rather use their devices for personal purposes rather than as learning tools.

\section{Conclusions}

This study has explored the factors that somehow determine students' low usage of MALL tools in learning vocabulary in English based on the results from a questionnaire and focus group discussions. The results showed that the majority of Romanian high school students have neutral attitudes towards using technology in their vocabulary learning. Additionally, several factors which are to determine students' low usage of MALL tools have been identified: pedagogical issues associated with mall tools, individual learning style, lack of teacher guidance, the lack of a MALL culture in mainstream schools, the level of motivation to use technology in language learning, the view of MALL tools as sources of entertaining rather than learning tools, a preference for apps that enable unconscious learning of vocabulary and the view of devices as belonging to students' personal 'space', not to their 'learning space'.

However, the participants of the current study are teenagers who own a personal device and use it outside school for communicating, entertainment, sharing or creating information. They use their device outside regular instruction sessions because their devices are generally banned in schools and their use is being discouraged. In conclusion, technology does not impact on students' learning or learning strategies unless educational authorities and teachers give value to these tools. The results also suggest that simply having access to technology enhanced tools does not necessarily mean that students will automatically use them for learning purposes or that it would have any impact on cognition or learning success.

These results echo the results of other researchers who claim that digital learners' engagement with technology enhanced tools and resources is limited and sporadic (Livingstone, 2009, Selwyn, 2009). Also it has been observed that digital learners' learning engagement is limited to texting, game playing, searching information on various websites (Luckin et al., 2009). Moreover, digital learners mostly use basic features of technology, such as texting, social networking and listening to music and not emerging technologies (e.g. Web 2.0), (Caruso and Kvavik, 2005, Kennedy et al.,2010). Digital learners are thought to lack the ability to use technology enhanced tools for academic purposes, (Rowlands et al., 2008).

Consequently, there are several features that define learners' digital engagement, respectively: lack of technology-related academic skills, a certain reluctance for using personal handheld devices for educational purposes, the perception of handheld devices and computers as content delivery tools rather than potential metacognitive tools, reluctance to mix formal and informal learning outside the classroom, unawareness as to the existence and use of various digital tools for vocabulary learning. 
Although Romanian students have at their disposal a wide range of digital instruments to learn and practice vocabulary, they would mostly use the least intrusive ones and the ones which do not imply extensive repetition of vocabulary items. An interesting aspect which emerged out of the findings was the fact that across the research, Romanian learners did not show to be passive receivers of technology since they have also uncovered a critical perspective as to their use of digital tools for learning purposes. The ownership and use of any digital device is not enough for students to start using these tools in formal language learning as long as there is no motivation, interest in English vocabulary learning and teacher guidance in the foreign language classroom.

\section{REFERENCES}

Abrams, Z. I. (2002). "Surfing to cross-cultural awareness: using Internet-mediated projects to explore cultural stereotypes". In Foreign Language Annals, 35(2): 141-160.

Al-Jarf, R. (2004). "The effects of Web-based learning on struggling EFL college writers". In Foreign Language Annals, 37(1): 49-57.

Blasszauer, J. (2001). "Collaborative projects via the Internet". In Teaching English with Technology: A Journal for Teachers of English, 1(6): 1-7.

Brandl, K. (2002). "Integrating Internet-based reading materials into the foreign language curriculum: from tacher-to-student-centered approaches". Language Learning and Technology, 6(3): 87-107.

Burston, J. (2013). "Mobile-assisted language learning: A selected annotated bibliography of implementation studies 1994-2012". Language Learning \& Technology, 17(3): 157-225.

Burston, J. (2014). "MALL: The pedagogical challenges." Computer Assisted Language Learning, 27(4): 344-357.

Caruso, J. B., \& Kvavik, R. B. (2005). "ECAR Study of Students and Information Technology, 2005: Convenience, Connection, Control, and Learning. Washington: EDUCAUSE", available from: https://library.educause.edu/ /media/files/library/2005/10/ecm0506-pdf.pdf, accessed 2nd March 2015.

Chikamatsu, N. (2003). "The effects of computer use on L2 Japanese writing." Foreign Language Annals, 36(1):114-127.

Chilianu, D. (2013). "Un studiu făcut recent în România arată DE CE INTRĂ LICEENI PE INTERNET”, available from: http://www.libertatea.ro/detalii/articol/studiu-tineri-liceeniinternet-474037.html, accessed 3 October, 2014.

Dias, J. (2002). “CELL phones in the classroom: Boon or bane?” C@lling Japan, Vol.10 (2) available from: http://jaltcall.org/cjo/10_1.pd , accessed 5 December, 2014.

Field, A. (2009). Discovering statistics using IBM SPSS statistics: And sex and drugs and rock ' $n$ ' roll. London: SAGE (Ed).

Gaved, M., Kukulska-Hulme, A., Jones, A., Scanlon, E., Dunwell, I., Lameras, P., \& Akiki, O. (2013). "Creating coherent incidental learning journeys on mobile devices through feedback and progress indicators".In QScience Proceedings mLearn2013, 13-16. doi:10.5339/ qproc.2013.mlearn.13, accessed 10 July 2015.

Giménez Lopez, J. L., Magal-Royo, T. \& García Laborda, J. (2009). Methods of adapting digital content for the learning process via mobile devices. World conference on educational sciences. New trends and issues in educational sciences. Nicosia, Cyprus. Procedia Social and Behavioral Sciences. Uzunboylu, H; Cavus, N, (Eds.) Vol.1, 1: 2673-2677. 
Godwin-Jones, R. (2011). “Mobile apps for language learning”, Language Learning \& Technology Vol.15 (2): 2-11.

Garcia Laborda, J. Frances Litzler, M. \& Castaneda, M. (2011) "Teaching English Language Learners through Technology". Language learning \& Technology, Vol. 15, 2: 39-41.

Jogan, M. K., Heredia, H. A., \& Aguilera, M. G. (2001). "Cross-cultural e-mail: Providing cultural input for the advanced foreign language student". Foreign Language Annals, Vol. 34(4): 341-346.

Kennedy, G., Judd, R., Dalgarnot, B., \& Waycott, J. (2010).”Beyond natives and immigrants: exploring types of net generation students". Journal of Computer Assisted Learning Vol.26 (5): 332-343.

Kolb, D. A. (1984). Experiential learning: Experience as the source of learning and development (Vol. 1). Englewood Cliffs, NJ (Eds), Prentice-Hall.

Lai, C. (2015), "Modeling teachers' influence on learners' self-directed use of technology for language learning outside the classroom". Computers \& Education Vol. 82: 74-83.

Livingstone, S. (2009). Children and the Internet: Great expectations, challenging realities. Cambridge: Polity Press (Eds).

Luckin, R., Bligh, B., Manches, A., Ainsworth, S., Crook, C., Noss, R. (2012). "Decoding Learning: The Proof, Promise and Potential of Digital Education", available from: http://www. nesta.org.uk/sites/default/files/decoding_learning_report.pdf, accessed 10 December, 2014

Luckin, R., Clark, W., Logan, K., Graber, R., Oliver, M., \& Mee, A. (2009).” Do Web 2.0 tools really open the door to learning: practices, perceptions and profiles of 11-16 year old learners." Learning, Media and Technology, Vol. 34(2): 87-104.

Macaro, E., Handley, Z., \& Walter, C. (2012). "A systematic review of CALL in English as a second or foreign language: Focus on primary and secondary education." Language Teaching, 45 (1), 1-43.

Meskill, C., \& Anthony, N. (2005). "Foreign language learning with CMC: forms of online instructional discourse in a hybrid Russian class." System, Vol.33(1): 89-105.

Pareja-Lora, A., Hita-Arús J., Read. T., Arancón-Rodriguez, P., Calle-Martínez, C., Pomposo, L., Monje-Martin, E., Barcena, E., (2013). "Toward Mobile Assisted Language Learning Apps for Professionals that Integrate Learning into the Daily Routine". In L. Bradley \& S. Thouësny (Eds.), 20 Years of EUROCALL: Learning from the Past, Looking to the Future. Proceedings of the 2013 EUROCALL Conference, Évora, Portugal (pp. 206-210). Dublin/Voillans (Eds): (C) Research-publishing.net.

Pegrum, M. (2014). Mobile learning: Languages, literacies and cultures. Basingstoke: Palgrave Macmillan (Eds).

Pemberton, L., \& Winter, M. (2011). "SIMOLA: Helping Language Learners Bridge the Gap". In Proceedings of the 4th Int. Conf. on ICT for Language-Learning. Florence, Italy.

Robinson, R. \& Reinhart, J. (2014). Digital Thinking and Mobile Teaching: Communicating, Collaborating, and Constructing in an Access Age. Denmark: Bookboon (Eds).

Rogers, E. M. (1962). Diffusion of innovations. New York, NY: The Free Press of Glencoe (Eds).

Rowlands, I., Nicholas, D., Williams, P., Huntington, P., Fieldhouse, M., Gunter, B., et al. (2008). "The Google generation: the information behavior of the researcher of the future." Aslib Proceedings, 60(4): 290-310.

Selwyn, N. (2009). "The digital native - Myth and reality". Aslib Proceedings: New Information Perspectives, 61(4): 364-379.

Stockwell, G. (2013). "Technology and motivation in English-language teaching and learning". In E. Ushioda (Ed.), International perspectives on motivation: Language learning and professional challenges (pp. 156-175). Basingstoke, UK: Palgrave Macmillan (Eds). 
Stockwell, G., \& Hubbard, P. (2013). "Some emerging principles for mobile-assisted language learning". Monterey, CA: The International Research Foundation for English Language Education. available from: http://www.tirfonline.org/wp content/uploads/2013/11/ TIRF_MALL_Papers_StockwellHubbard.pdf , accessed $18 \quad$ February 2015

Strainu, R., Georgescu, M., (2015). "Creative M-learning apps available on mobile markets", Proceedings of the 11th International Scientific Conference eLearning and Software for Education, Bucharest, April 23-24, 2015, available from: http://proceedings.elseconference. eu/, accessed 20 November 2015.

Teddlie, C., \& Tashakkori, A. (2009). Foundations of mixed methods research: Integrating quantitative and qualitative approaches in the social and behavioral sciences. Thousand Oaks, CA: Sage (Eds).

Underwood, J. (2014). "Seven challenges for open mobile vocabulary learning”. In Proceedings Ikasnabar 2014, available from: http://www.researchgate.net/publication/263239027, accessed 25 August 2015.

Underwood, J., Luckin, R., \& Winters, N. (2014). "MALL in the wild: Learners' designs for scaffolding vocabulary learning trajectories". In S. Jager, L. Bradley, E. J. Meima, \& S. Thouësny (Eds), CALL Design: Principles and Practice; Proceedings of the 2014 EUROCALL Conference, Groningen, The Netherlands (pp. 391-397). Dublin: Research-publishing. net. doi:10.14705/rpnet.2014.000251, accessed 14 August 2015.

Ushioda, E. (2013). "Motivation matters in mobile language learning: A brief commentary." Language Learning \& Technology, Vol.17(3): 1-5. Available from:http://ltt.msu.edu/issues/ october2013/commentary.pdf, accessed 2 February 2015.

Wong, L. (2013). “Analysis of students' after-school mobile-assisted artifact creation processes in a seamless language learning environment." Educational Technology \& Society, 16(2): 198-211. 